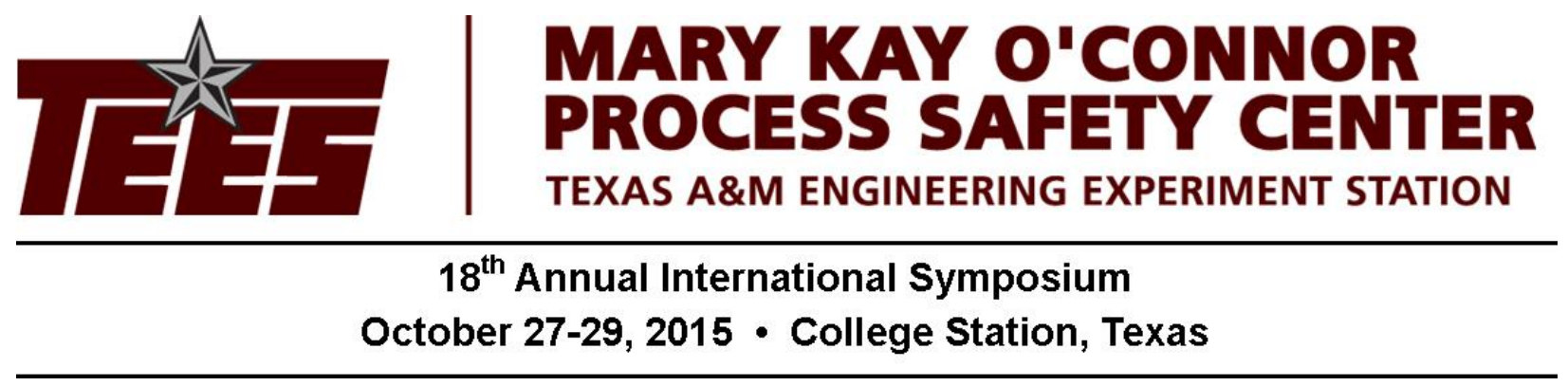

\title{
Critical Mitigation Element Methodology: An Approach to Achieving Consistent Risk Evaluation Results
}

\author{
Stewart Behie, Yuan Lu, George Buxton, Mark Slezak and Harold Schambach \\ Occidental Oil and Gas Corporation
}

\begin{abstract}
This paper introduces Critical Mitigation Element (CME) Methodology, an Occidental Oil and Gas Corporation (OOG) probability analysis methodology internally developed for the purpose of achieving consistent results when conducting risk evaluations throughout the company's worldwide upstream oil and gas operations. The methodology was developed as an efficient means of utilizing the strengths of Layer of Protection Analysis, LOPA. A CME is defined as a robust barrier (mitigation element) that reduces the probability by one level on the company's risk matrix or, in some cases, reduces the consequence level. In the past, OOG relied heavily on the industry historical approach to estimate event probability which resulted in very inconsistent estimations of event probability since the accuracy was based solely on the knowledge and experience of Process Hazards Review (PHR ${ }^{*}$ ) team members. In order to address this issue, OOG developed its CME Methodology which is similar to a LOPA approach but much more simplified in terms of determining what credit can be taken to reduce event scenario probability. The OOG CME methodology limits the layer of protection credit to those mitigation elements provided in a list of approved CMEs. CMEs are independent layers of protection that must be highly reliable upon demand. CMEs must be supported by verifiable field and test programs that are required to ensure overall CME integrity. These supporting elements are termed Key Mitigation Elements (KMEs). By using this CME methodology, OOG has demonstrated much greater consistency across their corporate-wide risk profile. Since prioritization of risk mitigation projects is based on risk levels, consistency provides an effective basis for resource allocation. OOG's implementation of the CME methodology has resulted in significantly improved PHA* accuracy and consistency and, ultimately, a more efficient and effective risk management program.
\end{abstract}

*Note: In this paper Process Hazards Review (PHR) and Process Hazards Analysis (PHA) are used synononously 


\section{Introduction}

OOG, a wholly owned subsidiary of Occidental Petroleum Corporation (Occidental) headquartered in Houston, Texas, is an international oil and gas exploration and production company with operations in the United States, the Middle East and Latin America. Occidental is the $4^{\text {th }}$ largest oil and gas company in the United States, based on market capitalization, and the largest producer of oil and associated liquids in the lower 48 states, with operations in Texas, New Mexico, North Dakota, and Colorado. Occidental has more than 44,000 employees and contractors worldwide. OOG is a leader in enhanced oil recovery operations and is the largest user of $\mathrm{CO}_{2}$ in North America. Risk management, process safety and asset integrity are integrated into every aspect of Occidental's businesses.

\section{The Need for Consistent Risk Assessments}

Risk assessments are a routine part of doing business in the oil and gas industry. Various techniques are used depending on the nature of the operation being assessed or the stage of development of a project under review. The requirement to conduct risk assessments is imbedded in risk policies, standards, procedures and guidelines (PSPGs) principally in Process Hazards Review (PHR), Management of Change (MOC) and the Permit to Work (PTW) systems. Inconsistencies in the results of risk assessments conducted by different Business Units (BU) were observed and recognized as a significant weakness in the risk program. The major culprit for these inconsistencies was traced to how event scenario probabilities were being assigned. Since the PHA program's inception about 25 years ago and until the CME methodology was implemented in 2011, event scenario probabilities were estimated using the industry historical methodology. The accuracy of this methodology relied upon the experience and expertise of PHA team members which varied significantly across operations and projects worldwide. For these same reasons, the inconsistent quality of PHAs has been noted by others such as the CSB and OSHA, who are pushing for use of more robust process hazards analysis methodologies.

A related issue with using the industry experience approach is auditability. Using this methodology, probabilities are set based on the PHA ${ }^{*}$ team's opinion; therefore, an auditor would have to question the team's judgement which is not scientific or within standard auditing protocol. To get consistent PHA results, the method used for setting probabilities must be based on facts (can a robust mitigation measure be demonstrated to be in place) rather than based on opinions.

\section{Evaluating Methodology Options}

Our goal was not only to find a robust, consistent methodology but also to implement a new methodology that would allow replacement of all existing PHAs with ground-up new PHAs within five years. When reviewing options to solve the PHA accuracy and consistence issues, LOPA was a very desirable option that, if properly applied, would provide the desired rigor and consistence to PHAs. However, adopting LOPA in the oil and gas company would not solve our major issue - the need for a high level of PHA team risk expertise and experience on every team worldwide. To properly implement the standard LOPA approach, special expertise would need to be developed and extensive initial and ongoing training would be needed in order to maintain LOPA leader competence. This would be a major challenge due to the dynamic nature of the company's operations and projects, and the need to have qualified risk engineers embedded across the geographic spread of operations worldwide. Replacing all existing PHAs with 
ground-up LOPA analysis would strain company risk team resources.

A ready solution that would meet both of these objectives did not seem to be available, so the corporate risk team set out to modify the standard LOPA approach to meet our needs. The standard LOPA must accommodate many different chemical and other hazardous processes. Since the OOG oil and gas processes are very homogeneous, the first thought was to develop standard levels of protection conventions that would simplify the LOPA application while still producing robust, consistent evaluations. However, this approach didn't meet either objective as there was too much subjectivity in applying the conventions. The team then determined that we might be able to actually define each layer of protection that may be credited for probability reduction. Pooling the knowledge and experience of our senior risk engineers across the company, the corporate risk team was able to assemble this list in a relatively short period of time. This list became our list of Critical Mitigation Elements or CMEs.

This approach to probability assignments also made the process auditable as very little subjectivity is involved when determining if a CME should be credited - the feature is in place or it is not.

\section{Oxy Risk Matrix}

The Oxy risk matrix, shown below in Figure 1, is a 5 x 5 matrix with consequence levels from 1 (lowest) to 5 (highest) for the six main consequence categories; namely, 1) people at the facility; 2) people outside the facility; 3) property damage and loss of revenue; 4) non-owned property damage; 5) environmental remediation; and 6) environmental wildlife and habitat impact.

There are five levels of probability ranging from 1 (least likely) to 5 (most likely). The probability of the event scenarios depends on the number of Critical Mitigation Elements (CMEs) in place. Without any CMEs in place and verified, the event scenario is 5. For every CME in place and verified, the probability level drops by one level. For example, an event scenario with 2 CMEs in place will have an associated probability of 3.

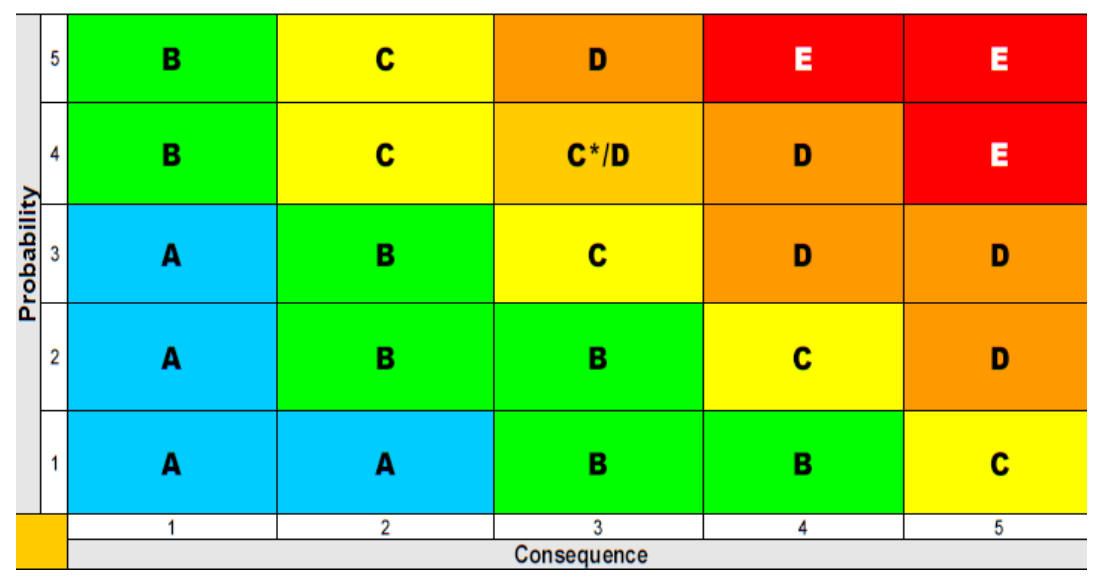

Figure 1 - The OOG Risk Matrix

\section{The Critical Mitigation Element (CME) Methodology}

A CME is defined as a robust barrier that reduces the probability of an event scenario by one 
level on the company's risk matrix (see Figure 1) or, in some cases, reduces the scenario consequences. CMEs are independent and reliable devices or systems that have the capability of preventing initiation of an event scenario, preventing loss of containment of a hazardous material, or substantially mitigating an undesired consequence. The use of the CME methodology provides consistent, repeatable and auditable bases for calculating probabilities of event scenarios. One credit is given for each CME. In addition, the failure of one CME may not prevent another CME from performing its function. Some typical examples of CMEs that might be applied, depending on the event scenario:

- Pressure relief systems

- Process interlocks (Emergency Shutdown Valves (ESDV's)

- Scrubbers and flares

- Detection and control systems

- Secondary containment systems

- Active and passive fire protection

- Fire and blast walls

- Receptor not present $>90 \%$ of the time

- Active fire protection systems

- Physical barriers

- Tank overflow line

- Buried pipeline indicator

- Layout / spacing / separation distances

- Car sealed or locked valve

- Check valve (except build-up of pressure)

- Redundancy

- Installed spare unit

- Elimination of ignition sources (proper electrical classification)

- Tank gas blanketing

- Innately safe design

- Human intervention if the system is monitored $100 \%$ of the time

The applicable CMEs are defined in several groups; namely, low probability initiating events (IF); prevention of the release (PR); prevention of ignition or explosion (IE); people consequence mitigation related to hydrocarbon releases (PC) and toxic releases (TC); environmental consequences mitigation (EV); and mitigation of property damage / loss of revenue (PD).

Table 1, below provides examples of one of the laminated CME summary sheets provided to each risk assessment team to assist in selecting appropriate CMEs. This summary sheet is for CMEs for vapor and gas release scenarios. Separate guidance documents have been developed to address CMEs related to drilling and well services operations based on event scenarios. 


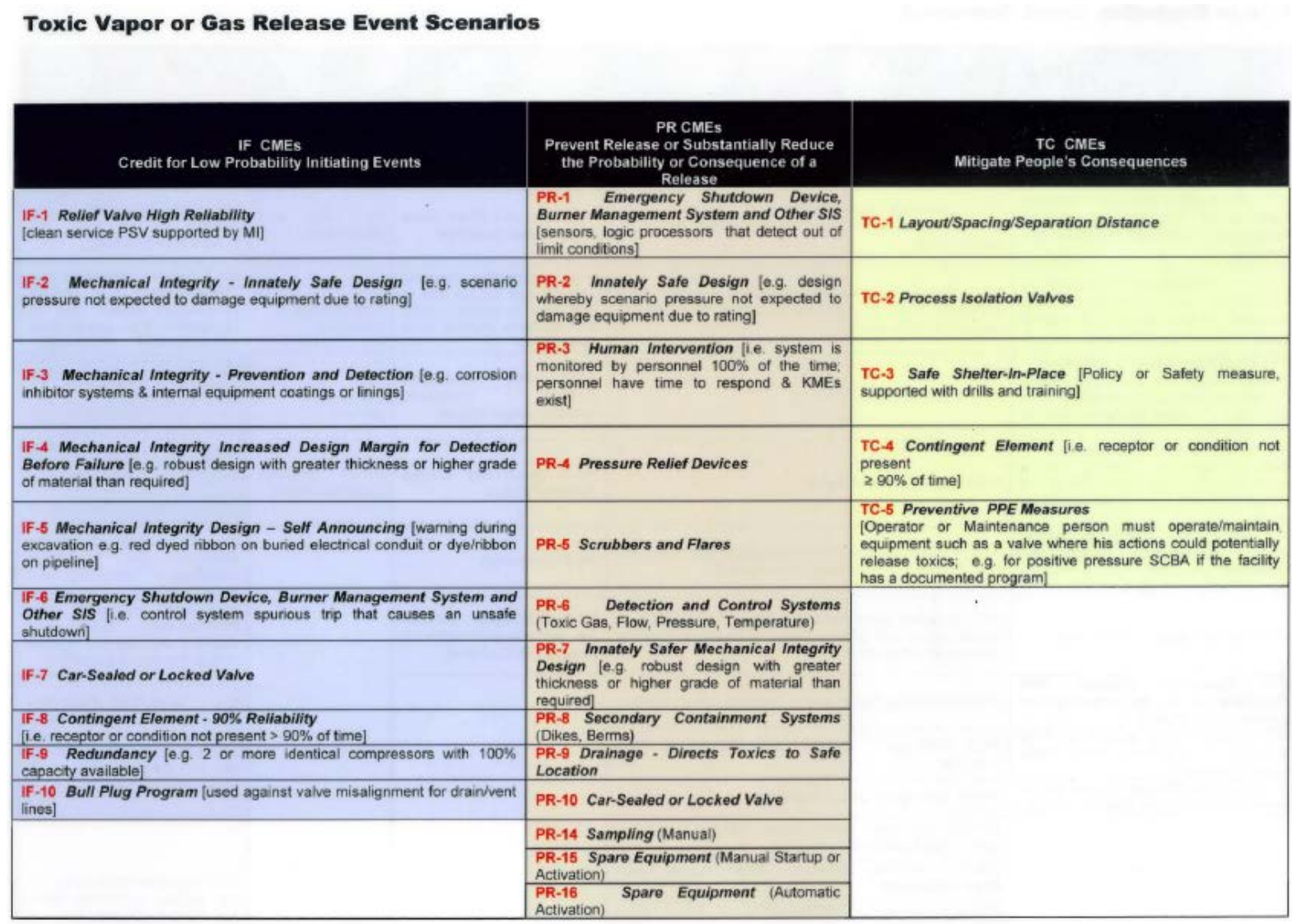

Table 1 - Examples of CMEs

Users may propose new CMEs to the corporate risk group; however, the original list has required little revision. The most significant addition has been new CMEs associated with evaluating field facilities since the original list was focused on traditional process plants.

With the new methodology and the associated training for all risk engineers, the results of risk assessments conducted by the various BUs across Oxy's oil and gas operations were much more consistent and comparable.

\section{Overview of Risk Management Program}

\section{The Business Unit Risk Evaluation Cycle}

Figure 3 below outlines the risk evaluation cycle that each unit must follow to meet the intent of the OOG corporate risk program requirements. Guidance documents have been prepared by the corporate risk group to define the requirements of each step of the risk evaluation cycle and training programs are in place to ensure that all the requirements are clearly defined and understood at the BU level. 


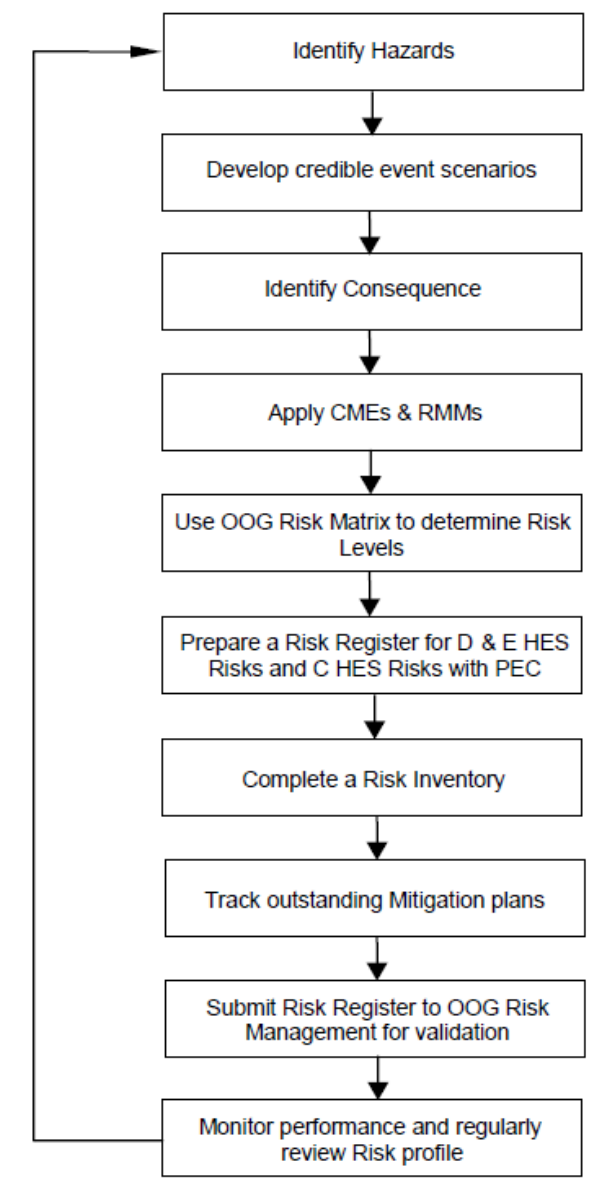

Figure 3 - The OOG Risk Evaluation Cycle

\section{Applying the CME Methodology}

Details of the application of OOG's CME methodology are outlined in this section with examples from risk assessments. The steps in the process are as follows:

- Event scenario development

- Identifying escalating events

- Release of hazard

- Escalating events after release of hazard

- Consequence level determination

\section{Event Scenario Development}

Development of credible Event Scenarios is a critical first step in evaluating Risk. An Event Scenario is not the worst case scenario but rather a realistic event that has a reasonable likelihood to result in harm to people, the environment or Company assets or earnings. 
An Event Scenario consists of initiating / escalating event(s) leading to a Hazard being "released" and the potential for adverse consequences. For each identified Hazard, an Event Scenario should be developed if there are any of the following credible Consequences:
a) Human Injury/Illness at a Facility
b) Human Injury Outside a Facility
c) Facility Property Damage and Loss of Revenue
d) Non-Owned Property Damage
e) Environmental Impairment: Clean-up / Remediation Cost
f) Environmental Impairment: Habitat or Wildlife Population

Where there is no credible potential for the above Consequences there is no credible Event Scenario. The proposed Event Scenario is deemed not credible and, therefore, Risk assessment is unnecessary.

Event scenarios are evaluated without consideration of any safeguards. The consequences are evaluated in terms of severity for each consequence category (e.g., People at a Facility). Each event scenario is then assigned a probability level for each credible consequence category in accordance with the corporate risk procedures using the CME methodology.

Figure 4 below depicts the progression of an Event Scenario.

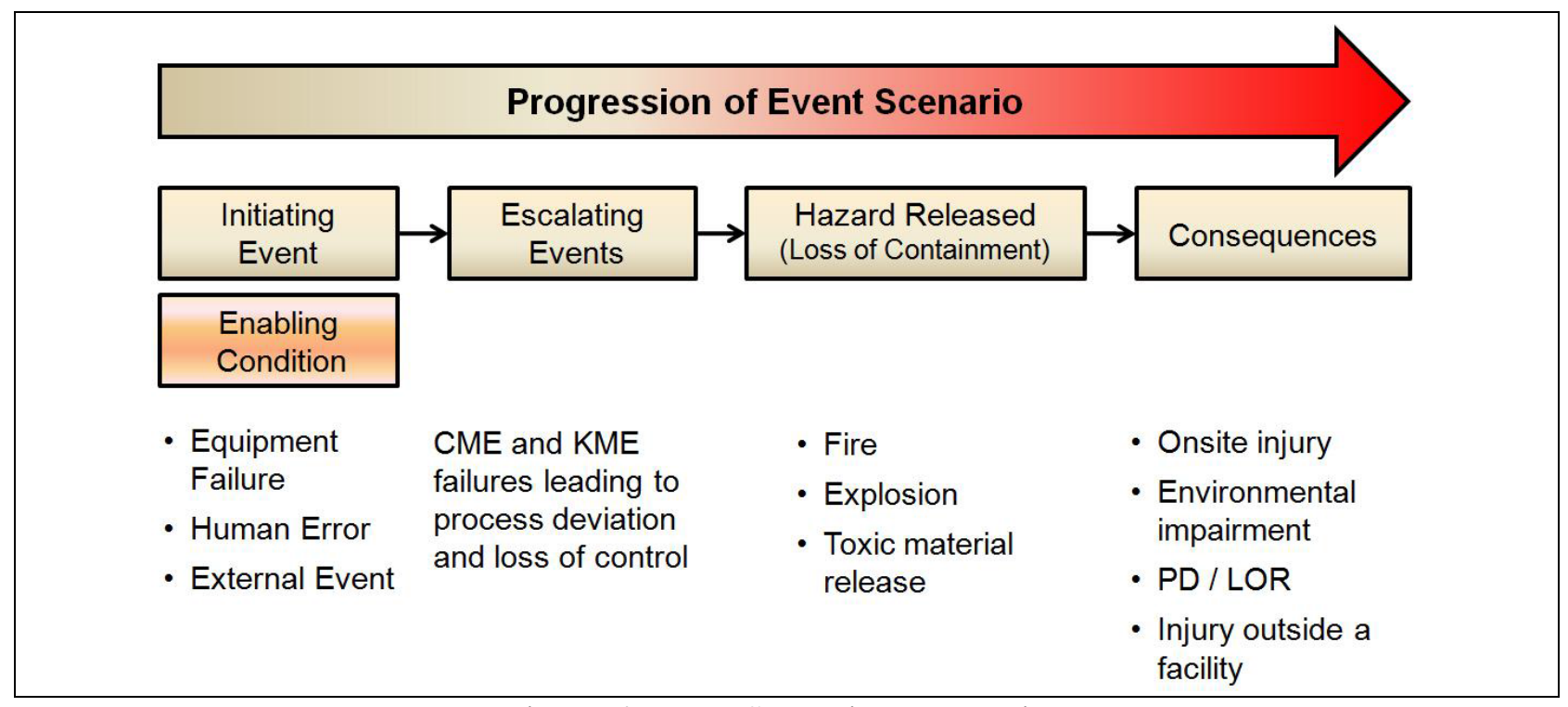

Figure 4 Event Scenario Progression

As shown in Figure 4, an initiating event such as an equipment failure or human error begins the sequence of events that leads to possible Consequences. For many Process Event Scenarios, multiple CMEs should function to prevent escalation of events. If the KMEs that support the CMEs are not appropriately maintained, the CMEs will tend to degrade over time, resulting in lower CME reliability or effectiveness. Under these conditions, an Event Scenario can progress and allow loss of control over a Hazard, typically in the form of loss of containment of a 
hydrocarbon or toxic material. After a Hazard is "released", there should be other CMEs available that are designed to prevent or mitigate possible Consequences of the Hazard. However, if these CMEs are not effective, then the Event Scenario may progress until damage or harm occurs, resulting in an ultimate undesired Consequence. In some cases, if an Event Scenario is not stopped from progressing, then knock-on effects may occur whereby the Consequences initiate another Event Scenario(s) having more severe or different Consequences (domino effect). Therefore, it is desirable to place priority on CMEs and supporting KMEs to prevent the Hazard from being released.

For some Event Scenarios, an enabling condition must exist concurrent with the initiating event in order for the scenario to commence.

Event scenario development is assisted by reviewing past incidents at OOG and other operators, facility citing studies, lessons learned from past incidents, pervious hazard reviews and risk assessments and past experiences from longer-term staff.

\section{Identifying Escalating Events}

Escalating events are the subsequent series of events that could occur following an initiating event in the absence of any CMEs to stop the progression of events. In this step the team should assume that all CMEs fail to function as designed even if they are very robust.

\section{Release of Hazard}

The potential for Consequences exist when there is loss of control over a Hazard, allowing it to be "released." For Processes, this typically involves loss of containment of process materials, though it could also involve mechanical loss of containment. In this step, the team should describe the loss of control over the Hazard and provide a relative scale of the Hazard being released.

For a case of overpressure (i.e., system/process pressure that exceeds the design pressure) a loss of containment scenario must be considered. However, consideration should be given to factors that may influence the size of the release.

\section{Identification of Escalating Events after Release of Hazard}

Following release of the Hazard, the team should identify the subsequent series of events that could occur, if any, again assuming the absence of any CMEs to stop the progression of events. In many cases, such as an explosion, there are no escalating events except for possible knock-on effects.

\section{Determining of Consequence of Events}

Consequences can be developed once a Hazard has been released and the escalating events, if any, are identified. It is important to evaluate Consequences under the assumption that CMEs and KMEs that may be in place to prevent escalation of the event do not function as intended. This approach should then lead to the credible worst case Consequences for the Event Scenario. Typically, there is an intermediate Consequence from a release of a hydrocarbon - a fire, explosion or both. The team should be cognizant of possible knock-on effects that can occur from the intermediate Consequence. The final Consequences can be damage or harm in the form 
of injury to people, environmental impairment, damage to company assets/loss of production revenue or damage to third-party property.

\section{Example \#1}

In this example a HAZOP team is doing a risk assessment of a Low Pressure (LP) production separator. For the deviation of no / low flow caused by a Pressure Control Valve (PCV) failing open, several possible consequences were identified as indicated in the worksheet from the analysis (Figure 5). One of the potential significant consequences was the over pressurizing of separator V-125 leading to vessel rupture, the release of HC and possible fire / explosion. The consequence for "People at the Facility" was judged to be a consequence level " 3 " which equates to one "Potential Incapacitating Injury". As indicated in Figure 5, two CMEs were identified namely;

- A downstream pressure transmitter PT-1001 which is interlocked to and closes inlet valve XV-1001 (CME PR 6)

- A pressure safety valve (PSV) on the separator set at 90 psi designed to handle full flow (CME PR 4)

These two CMEs reduce the probability of unwanted consequences from 5 to 3 which results in a risk ranking of " $C$ " (see Figure 1 - Consequence 3 and Probability 3 ). The risk assessment team, made the recommendation to add a secondary pressure switch to close the vessel inlet Emergency Shutdown Valve (ESD-1) to provide additional mitigation for this scenario. If this CME is implemented, the risk ranking for this event scenario would drop to a " $\mathrm{B}$ ". As noted, two KMEs were identified related to training and procedures. It is important to list the KMEs that support the CMEs in the worksheet. 


\begin{tabular}{|c|c|c|c|c|c|c|c|c|c|c|c|c|c|}
\hline \multicolumn{14}{|c|}{$\begin{array}{l}\text { Location: Houston, TX USA } \\
\text { Unit: ABC Facility } \\
\text { Date: } 1.10 / 7 / 2013 \\
\text { Node: 1. Flow to LP Production Separator }\end{array}$} \\
\hline \multirow{2}{*}{ Deviation } & \multirow{2}{*}{ Causes } & \multirow{2}{*}{ Consequences } & \multirow{2}{*}{$\begin{array}{l}\text { Consequence } \\
\text { Category }\end{array}$} & \multirow[t]{2}{*}{ PEC } & \multirow{2}{*}{ Mitigation (CME/KME) } & \multirow{2}{*}{$\begin{array}{l}\text { CME } \\
\text { Name }\end{array}$} & \multicolumn{3}{|c|}{ Initial Risk } & \multirow{2}{*}{ Recommendations } & \multicolumn{3}{|c|}{$\begin{array}{l}\text { Estimated Residual } \\
\text { Risk }\end{array}$} \\
\hline & & & & & & & C & $\mathbf{P}$ & RL & & c & $\mathrm{P}$ & RL \\
\hline \multirow[t]{12}{*}{ 1. No / Low Flow } & \multirow[t]{12}{*}{$\begin{array}{l}\text { 1. PCV-1001 fails open (on Line } \\
\text { 4"-NCP-1001) }\end{array}$} & \multirow{4}{*}{$\begin{array}{l}\text { 1.1. Potential for upto } 250 \mathrm{psig} \\
\text { pressure to the LP Production } \\
\text { Separator V-125 rated for } 100 \\
\text { psig leading to vessel rupture } \\
\text { with and release of } \\
\text { hydrocarbons with possible } \\
\text { fire/explosion }\end{array}$} & \multirow[t]{4}{*}{$\begin{array}{l}\text { People At the } \\
\text { Facility }\end{array}$} & \multirow[t]{4}{*}{ NA } & $\begin{array}{l}\text { 1.1.1. PT-1001 downstream of PCV-1001 with } \\
\text { interlock to close XV- } 1001 \text { on the inlet side } \\
\text { of the LP Production Separator V-125 (CME } \\
\text { 1) }\end{array}$ & PR-6 & \multirow[t]{4}{*}{3} & \multirow[t]{4}{*}{3} & \multirow[t]{4}{*}{ c } & \multirow{4}{*}{$\begin{array}{l}\text { 1. Consider installing a secondary } \\
\text { pressure switch that shuts the } \\
\text { inlet ESD-1 to the facility in a } \\
\text { hard wired fashion independent } \\
\text { of the PLC. The issue is that } \\
\text { PCV-1001 fails open leading to } \\
250 \text { psig pressure to the LP } \\
\text { Production Separator V-125 } \\
\text { rated for } 100 \text { psig leading to } \\
\text { vessel rupture. (CME } 3 \text { ) }\end{array}$} & \multirow[t]{4}{*}{3} & \multirow[t]{4}{*}{2} & \multirow[t]{4}{*}{$B$} \\
\hline & & & & & $\begin{array}{l}\text { 1.1. PSV-125 on the LP Production Separator V- } \\
125 \text { set @ } 90 \text { psig sized to handle full flow } \\
\text { through PCV-0001 of } 1 \text { MM SCFD (CME 2) }\end{array}$ & PR-4 & & & & & & & \\
\hline & & & & & $\begin{array}{l}\text { 1.1.3. Operating Procedure OP-111, Section } 1.1 \text {, } \\
\text { Step } 12 \text { (KME) }\end{array}$ & KME & & & & & & & \\
\hline & & & & & 1.1.4. 4. Operator Training on Procedure (KME) & KME & & & & & & & \\
\hline & & $\begin{array}{l}\text { 1.2. No hazardous consequences } \\
\text { (remote location) }\end{array}$ & $\begin{array}{l}\text { People Outside } \\
\text { the Facility }\end{array}$ & NA & & & & & & & & & \\
\hline & & \multirow{2}{*}{$\begin{array}{l}\text { 1.3. Property damage and loss of } \\
\text { revenue (less than < } \$ 20 \mathrm{MM} \text { ) } \\
\text { - Vessel damage estimated at } \\
\$ 500 \mathrm{M} \text { with loss of } \\
\text { production of } 7 \text { days } \times 1500 \\
\text { barrel/day } \times \$ 85 / \text { barrel }\end{array}$} & \multirow[t]{2}{*}{$\begin{array}{l}\text { Property Damage / } \\
\text { Loss of Revenue }\end{array}$} & \multirow[t]{2}{*}{ NA } & $\begin{array}{l}\text { 1.3.1. PT-1001 downstream of PCV-1001 with } \\
\text { interlock to close XV- } 1001 \text { on the inlet side } \\
\text { of the LP Production Separator V-125 (CME } \\
\text { 1) }\end{array}$ & PR-6 & \multirow[t]{2}{*}{2} & \multirow[t]{2}{*}{3} & \multirow[t]{2}{*}{ B } & & & & \\
\hline & & & & & $\begin{array}{l}\text { 1.3.2. PSV-125 on the LP Production Separator V- } \\
125 \text { set @ } 90 \text { psig sized to handle full flow } \\
\text { through PCV-0001 of } 1 \text { MM SCFD (CME 2) }\end{array}$ & PR-4 & & & & & & & \\
\hline & & $\begin{array}{l}\text { 1.4. No hazardous consequences } \\
\text { (remote location) }\end{array}$ & $\begin{array}{l}\text { Non-Owned } \\
\text { Property Damage }\end{array}$ & NA & & & & & & & & & \\
\hline & & \multirow[t]{2}{*}{$\begin{array}{l}\text { 1.5. Release of oil/water/gas to } \\
\text { the ground and atmosphere }\end{array}$} & \multirow[t]{2}{*}{$\begin{array}{l}\text { Environment: } \\
\text { Remediation }\end{array}$} & \multirow[t]{2}{*}{ NA } & $\begin{array}{l}\text { 1.5.1. PT-1001 downstream of PCV-1001 with } \\
\text { interlock to close XV- } 1001 \text { on the inlet side } \\
\text { of the LP Production Separator V-125 (CME } \\
\text { 1) }\end{array}$ & PR-6 & 1 & 3 & A & & & & \\
\hline & & & & & $\begin{array}{l}\text { 1.5.2. PSV-125 on the LP Production Separator V- } \\
125 \text { set @ } 90 \text { psig sized to handle full flow } \\
\text { through PCV-0001 of } 1 \text { MM SCFD (CME 2) }\end{array}$ & PR-4 & & & & & & & \\
\hline & & $\begin{array}{l}\text { 1.6. Potential impact to protected } \\
\text { species in the area of }<\$ 500 \\
M\end{array}$ & $\begin{array}{l}\text { Environment: Wild } \\
\text { life and Habitat }\end{array}$ & NA & $\begin{array}{l}\text { 1.6.1. PT-1001 downstream of PCV-1001 with } \\
\text { interlock to close XV- } 1001 \text { on the inlet side } \\
\text { of the LP Production Separator V-125 (CME } \\
\text { 1) }\end{array}$ & PR-6 & 1 & 3 & A & & & & \\
\hline & & & & & $\begin{array}{l}\text { 1.6.2. PSV-125 on the LP Production Separator V- } \\
125 \text { set @ } 90 \text { psig sized to handle full flow } \\
\text { through PCV-0001 of } 1 \text { MM SCFD (CME 2) }\end{array}$ & PR-4 & & & & & & & \\
\hline
\end{tabular}

Figure 5 - Example 1 HAZOP Worksheet

The Bow-tie representation of the Example \#1 worksheet for no/low flow is shown below in Figure 6. The two existing CMEs are shown in grey are in the category of Preventing Release (PR). Adding the recommended CME (PR-1 shown in yellow) reduces the existing risk level from " $C$ " to " $B$ ". All six consequence categories are shown in the bowtie even though two categories have no consequence (i.e. NC). The risk level for the three other consequence categories were unaffected by the recommendations and hence did not change. 


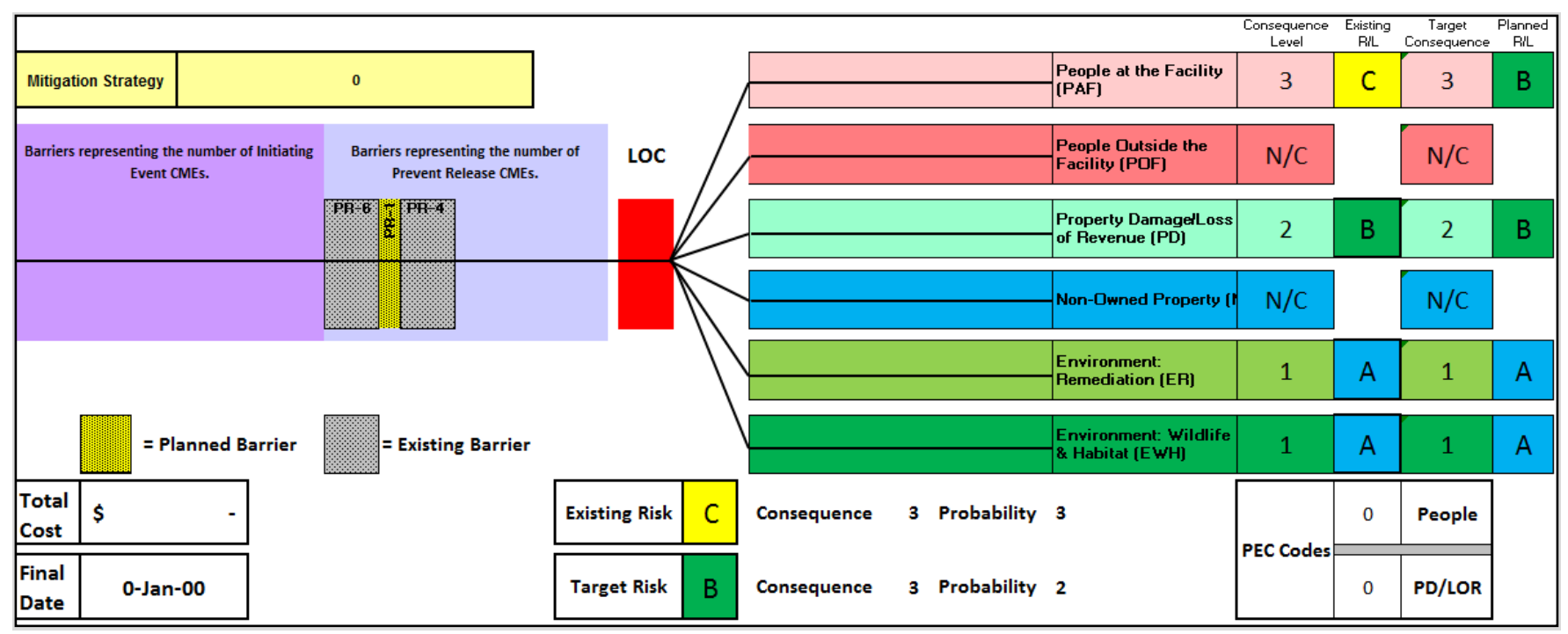

Figure 6 - Bowtie Representation for Example \#1

\section{Example \#2}

In this example the team was using a "What-If?" technique to conduct a risk assessment of a well fluids separator system (see Figure 7). For the second "What-If?" scenario of a low oil level in the oil chamber caused by the failure of Level Indicator Controller (LIC-0963), the consequence identified is pump damage and production loss. The consequence level was identified as " 4 " largely because of the long period of production loss (180 days) while a new pump is purchased and installed. There were two CMEs identified as noted in Figure 7.

- level transmitter (LZIT-0930; CME 1) which will trip the pump on low oil level, and

- flow alarm (FIA-00737; CME 3) which signals the operator to stop the pump. This CME is only valid if the operator is available for $90 \%$ of the time or more (i.e. such as a panel operator).

With these two CMEs credits, the probability is 3, giving an existing risk ranking of "D" (see Figure 1). The team recommended that a spare pump be purchased and maintained in the warehouse inventory. If this recommendation is acted upon, the production loss will be substantially lower with the spare pump on site ( 7 days to replace the pump). This reduces the consequence level to " 2 " and hence the risk ranking to " $\mathrm{B}$ ”. 


\begin{tabular}{|c|c|c|c|c|c|c|c|c|c|c|c|}
\hline \multirow{2}{*}{ What ifs } & \multirow{2}{*}{ Causes } & \multirow{2}{*}{$\begin{array}{c}\text { Consequence } \\
\text { Category }\end{array}$} & \multirow{2}{*}{ Consequences } & \multirow{2}{*}{ Mitigation } & \multicolumn{3}{|c|}{$\begin{array}{l}\text { Initial } \\
\text { Risk }\end{array}$} & \multirow{2}{*}{ Recommendations } & \multicolumn{3}{|c|}{$\begin{array}{l}\text { Residual } \\
\text { Risk }\end{array}$} \\
\hline & & & & & C & $\mathbf{P}$ & $\mathbf{R}$ & & C & $\mathbf{P}$ & $\mathbf{R}$ \\
\hline $\begin{array}{l}\text { Hi Blanket } \\
\text { Gas }\end{array}$ & $\begin{array}{l}\text { PV-01319A stuck } \\
\text { open }\end{array}$ & Onsite Inj/III & $\begin{array}{l}375 \text { psig gas } \\
\text { introduced into the } \\
\text { FWKO drum that is } \\
\text { designed for } 168 \text { psig } \\
\text { resulting in vessel } \\
\text { failure, LOC and } \\
\text { potential fire from } \\
\text { released HC or vapor } \\
\text { cloud }\end{array}$ & $\begin{array}{l}\text { PZIT-01320 interlocked to UZV- } \\
02025 \text { on HH pressure - via SIS } \\
\text { system (CME 1) } \\
\text { PIT-01319 control PV-01319B } \\
\text { vent to flare - via DCS (CME 2) } \\
\text { RV-00282A relief valve (CME 3) }\end{array}$ & 4 & 2 & C & $\begin{array}{l}\text { Consider the addition of } \\
\text { pressure regulator/ control } \\
\text { valve on HP fuel gas } \\
\text { header (CME) }\end{array}$ & 4 & 1 & B \\
\hline $\begin{array}{l}\text { Lo Oil Level in } \\
\text { the Oil } \\
\text { Chamber }\end{array}$ & $\begin{array}{l}\text { LIC-0963 fails high } \\
\text { (on Delta V) }\end{array}$ & Onsite PD/LOR & $\begin{array}{l}\text { Potential pump P- } \\
1125 \text { damage } \\
\text { leading to loss of } \\
\text { production }\end{array}$ & $\begin{array}{l}\text { LZIT-0930 interlocked to trip } \\
\text { pumps on low oil level - field } \\
\text { local (CME 1) } \\
\text { FIA-00737 low flow alarm on the } \\
\text { common discharge header } \\
\text { coupled with operator } \\
\text { intervention - on Delta V (CME } \\
\text { 2) }\end{array}$ & 4 & 3 & $\mathrm{D}$ & $\begin{array}{l}\text { Consider purchasing a } \\
\text { spare crude transfer pump } \\
\text { (high consequence failure } \\
\text { item). (Having a spare } \\
\text { warehouse pump will } \\
\text { reduce the downtime from } \\
180 \text { days to } 7 \text { days for } \\
\text { pump replacement) }\end{array}$ & 2 & 3 & B \\
\hline $\begin{array}{l}\text { Lower } \\
\text { Pressure }\end{array}$ & $\begin{array}{l}\text { Bas blanketing } \\
\text { valve PV-0940 fails } \\
\text { closed }\end{array}$ & Onsite PD/LOR & $\begin{array}{l}\text { Potential for air } \\
\text { ingress into clarifier } \\
\text { resulting in increased } \\
\text { corrosion of wetted } \\
\text { parts }\end{array}$ & $\begin{array}{l}\text { Wetted parts are epoxy coated } \\
\text { (CME 1) } \\
\text { Low pressure alarm on PIT- } \\
09058 \text { with operator intervention } \\
\text { - on DCS (CME 2) }\end{array}$ & 2 & 3 & B & & & & \\
\hline
\end{tabular}

Figure 7 Example 2 - Field Separator System

The Bow-tie representation of the Example \#2 worksheet for Low Oil level in the oil chamber is shown below in Figure 8. The two existing CMEs are in the category of Preventing Release (PR) as show in grey. By purchasing a spare pump and having it available on site, the consequence level in the Property Damage / Loss of Revenue category is reduced from " $D$ " to " $B$ " is shown in the Bowtie.

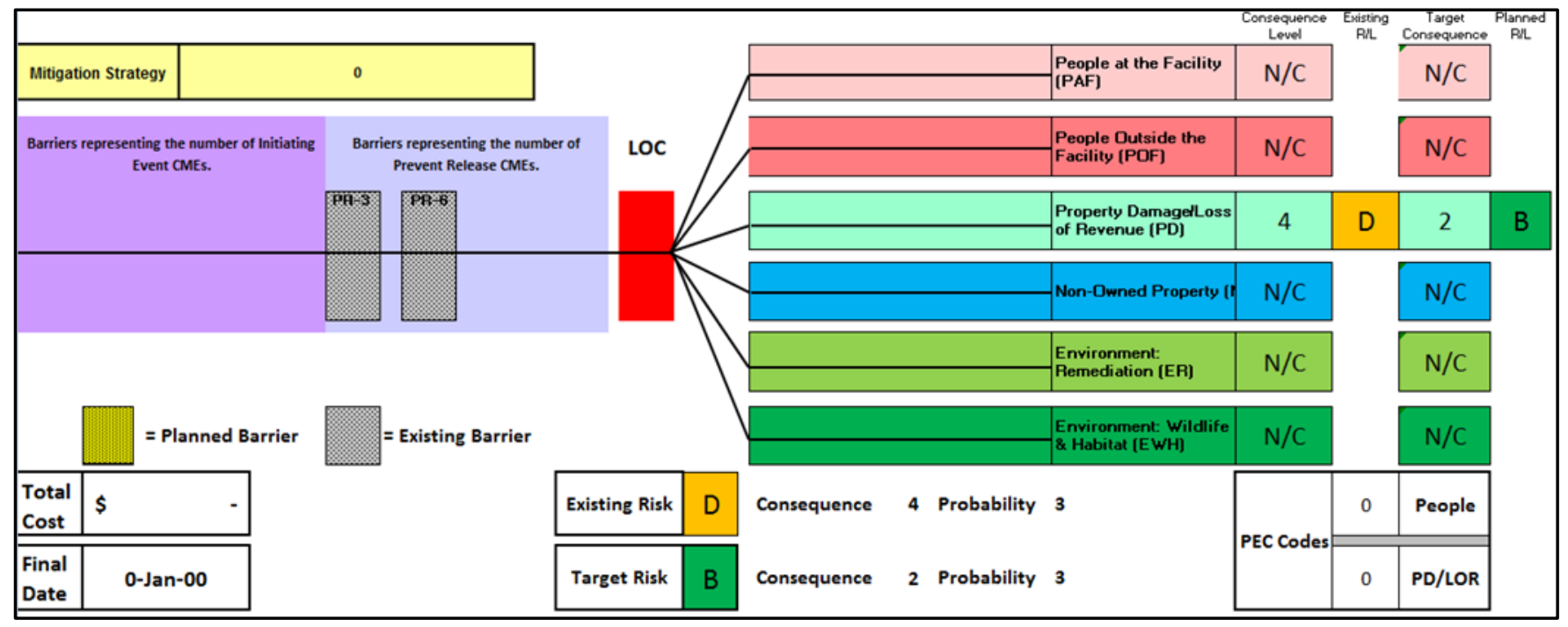

Figure 8 - Bowtie Representation for Example \#2 


\section{Example \#3}

Figure 9 shows a page from the work sheets from a HAZOP of a gas plant suction scrubber, V101, for the deviation of high level. The cause of the high level is liquid carry over from the slug catchers V-107 and V-107A. The consequence of this liquid carryover is subsequent liquid carryover past the suction scrubber to the downstream compressor leading to compressor damage and potentially a gas release to the environment leading to possible fires and explosion. The consequence for this event scenario for the category "Human Injury/Illness at a Facility", was estimated to be a consequence level " 4 ” which equate to 2 potentially incapacitating injuries. The only CME in that can be credited is the fire and gas detection system which on activation will trip the compressor and overall gas plant. There is the high level switch on the suction scrubber, LSHH-102, but the team could not confirm whether this level switch initiated executive action to trip the compressor. As a result the team could not take credit for this level switch as a CME. The probability with one CME is " 4 " and hence the risk ranking is " $D$ ". The recommendations made were to:

- Add all of the fire and gas detectors into the maintenance management system (Maximo) to ensure PM tracking.

- Re-design the liquid boot system which is configured in such a manner to prevent automatic level control in the suction scrubber.

- Confirm the executive action of LSHH-102 and ensure that it is interlocked to trip the compressor on high, high level

With these additional CMEs in place the probability of occurrence drops to "2" and hence the risk ranking is reduced to a " $\mathrm{C}$ ”. 


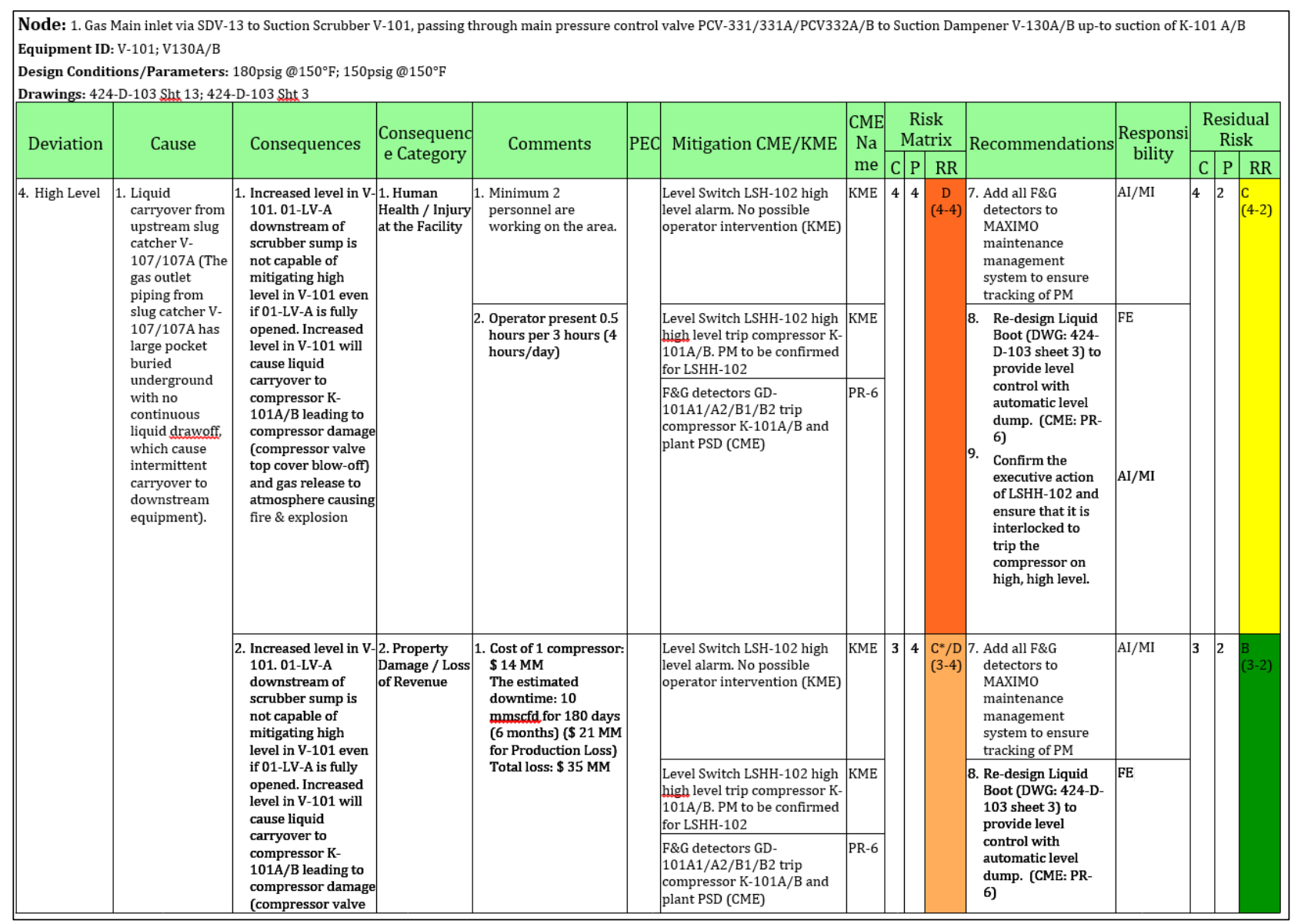

Figure 9 Example 3 - Gas Plant Suction Scrubber

The Bow-tie representation of the Example \#3 worksheet for High Level in the suction scrubber is shown below in Figure 10 below. The only existing and confirmed CME in place is in the Preventing Release category. The consequence to People at the facility category is reduced from " $D$ " to "C" when the two proposed CMEs shown in yellow in the Bowtie are put in place and confirmed. 


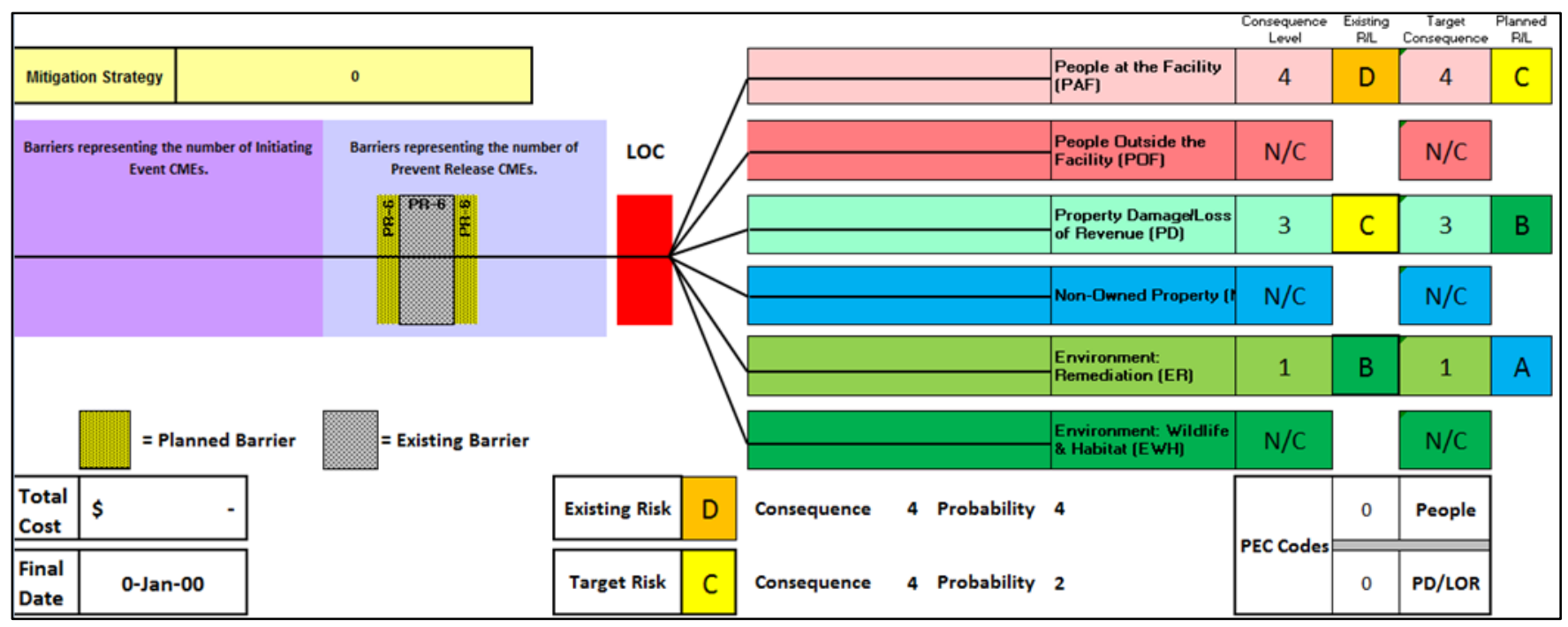

Figure 10 - Bowtie Representation for Example \#3

\section{Key Mitigation Elements (KME)}

Key Mitigation Elements are characterized into two main categories: 1) mitigation measures that could mitigate an event scenario but are not robust enough to qualify as a CME, and 2) equipment, design features, specifications, inspection and maintenance routines, and operating parameters that are necessary to achieve and maintain the credited reliability level of Critical Mitigation Elements (CMEs).

As CMEs are robust mitigation measures that significantly reduce the Probability of a Consequence, their integrity must be maintained in order to achieve the intended Risk Level. Further, if the impact of supporting KMEs is not known or not clear to those who maintain them, the CMEs mitigation capabilities may not be robust or may erode. Any equipment credited as a CME must be classified as HES Critical Equipment in the company’s Asset/Mechanical Integrity Program and receive the highest priority for maintenance, testing, calibration, etc.

Each KME that supports a CME must be mapped to a plant procedure or other documents, and the group number must be referenced on the PHR and Risk Register rather than listing them every time the documents require them. The unique KMEs must be listed in addition to the group(s).

The supporting documents that maintain KMEs must be flagged so that those revising the documents are alerted to their significance (i.e., the MOC team must know to include this in their analysis).

Examples of KMEs that mitigate a risk but do not meet CME standards include:

- Training and Certification

- Procedures

- Communications

- Signage 
Examples of KMEs that support CMEs:

- Requirement that Pressure Safety Valves be designed in accordance with API 520

- Equipment designated as HES Critical Equipment and, therefore, requiring that integrity and reliability be maintained at the highest level

- Documented car seal inspection program to verify car-seals in-place on block valves under PSVs.

OOG HES Risk Register: For each facility / system evaluated to have potential or validated risks greater than level C, an OOG HES risk register must be completed for each event scenario. The risk registers are entered and maintained in a corporate database. Event scenarios may be grouped into a single risk registry entry when they have substantially similar results with the same mitigation and management plan. Business Units are responsible for ensuring that the OOG HES Risk Registers are kept current by revising them when HES Risks are impacted by changes such as facility modifications, completion of mitigation plans, substantial fluctuations in the value of or revenue from the facility/system, etc.

Risk Inventory and Risk Reporting: Each BU is required to maintain an inventory of D and E level risks which is essentially a compilation of validated HES risk registers. The BU risk inventories are viewed in real time by the corporate risk group who are alerted when changes are made in the risk register database. The documentation must include: event scenario, existing applicable CMEs and KMEs, planned CMEs and KMEs as well as consequence, probability and risk levels (current and target risk levels). The BU must report any new $\mathrm{C}, \mathrm{D}$ or $\mathrm{E}$ level risks within 60 days to the corporate risk group. A team of senior risk engineers will conduct a revalidation of all $\mathrm{C}, \mathrm{D}$ and $\mathrm{E}$ level risk prior to their registry in the corporate risk inventory. Annually, each BU prepares a comprehensive risk inventory report which is signed by the BU's general manager and submitted to the corporate risk group. The risk group consolidates the BUs' annual risk reports into an OOG risk inventory which is reviewed with corporate executives.

Tracking Outstanding Risk Mitigation Plans: Tracking of planned CMEs and KMEs is essential to the success of maintaining up-to-date risk inventories. Mitigation plans, target dates and cost estimates are entered into the planned CMEs tab of each Risk Register. Risk mitigation plans are entered in the corporate HES tracking system. KMEs that support CMEs may be grouped, documented and referenced as a group to improve efficiency. The risk and asset integrity groups work closely together to assure KMEs are supported by robust maintenance and mechanical integrity programs.

HES Risk Response: The risk level determined for each event scenario will determine the risk response. When a potential or validated C, D or E level risk is identified, immediate action must be taken to assure that all practical measures are assessed to assure existing mitigation is robust (e.g., operating parameters, AI/MI routines and set points/calibrations are verified to be appropriate and up to date; interim operating options that would avoid or mitigate the risk are evaluated; etc.). OOG's risk program does not set ALARP or tolerable risk ranges. Rather, risk are elevated to the appropriate organizational level for acceptance (i.e., analogous to an AFE process for capital allocation). Lower level risks are managed at the BU level, mid-level risks are managed at the Business Segment level and the higher level risks are managed at the corporate level with Board of Directors oversight. Mitigation plans are assessed against BUs' 
capital plans during budget reviews.

\section{Training Plan}

Training is a key component to ensuring that the CME methodology is well understood and implemented in a consistent manner across all Business Units. PHA leaders are required to be trained in both the PHA methodology and the CME methodology before they are allowed to function in this capacity. An overview of the PHA methodology and CME training is provided to those assigned as PHA team members.

\section{Continuing improvement}

Each risk register is verified by the BU lead risk engineer and validated by the corporate risk group. BU self-audits, targeted external reviews and corporate HES audits evaluate both program performance and compliance.

Feedback on the CME methodology's performance is used for implementing improvements. For example, a detailed guideline was developed to improve the quality and consistency when applying CME credits for various basic plant and safety instrumented control system configurations. This was a cooperative effort between the corporate automation and risk engineering groups and many of the BU experts that have practical experience with these systems.

\section{Conclusion}

With this new CME methodology and the associated training for all risk engineers, the results of risk assessments conducted by the various BUs across the Occidental Oil and Gas world have been much more consistent, comparable and auditable. Consistency is very important to OOG's risk management program since risk levels produced by PHRs are the basis for risk management decisions including resource allocation. The methodology has also proven to be efficient as PHA leaders and team members can be easily trained to apply it. Over the past five years, new ground-up CME PHAs have replaced prior PHAs that used the industry experience approach. The existing risk inventory is much more robust and line managers no longer view PHA results as arbitrary and subjective. The risk community can present the company's risk inventory to executive management as a validated and consistent reference tool. 